\title{
Erratum: Structure of and influence of a tick complement inhibitor on human complement component 5
}

Folmer Fredslund, Nick S Laursen, Pietro Roversi, Lasse Jenner, Cristiano L P Oliveira, Jan S Pedersen, Miles A Nunn, Susan M Lea, Richard Discipio, Lars Sottrup-Jensen \& Gregers R Andersen

Nat. Immunol. 9, 753-760 (2008); published online 8 June 2008; corrected after print 20 June 2008

In the version of this article initially published, the numbers in the ' $R_{\text {sym }}$ ' row in Table 1 are in the wrong columns. The error has been corrected in the HTML and PDF versions of the article. 